\title{
Rectal bezoars in children
}

\section{Bryanne Minty BSc, Len Kelly MD M Clin Sci}

Previously published at www.cmaj.ca

A previously well eight-year-old boy was brought to the emergency department with a three-day history of constipation. He had consumed three handfuls of flavoured unshelled sunflower seeds four days previously. His mother had unsuccessfully tried several sodium biphosphate and sodium phosphate enemas at home, as well as the use of bran to aid defecation. On examination, the patient's abdomen was soft and nontender with normal bowel sounds. A bolus of stool mixed with unshelled sunflower seeds was visible at the anus.

A radiograph of the abdomen showed stool extending from the descending colon down to the rectum, which contained a large mass (Figure 1). Oral phosphate soda and a mineral oil enema were ineffective. The patient was taken to the operating room for digital and instrumental extraction under general anesthesia. He was monitored in hospital for 24 hours and discharged when he was taking liquids and passing soft stool.

A bezoar is a solid mass formed in the gastrointestinal tract as a result of the consumption of indigestible or poorly digestible substances. Bezoars most commonly form in the stomach, but can occur in the small intestine and, rarely, in the colon or rectum. They are usually classified according to the material of which they are derived, for example, trichobezoars (hair), lactobezoars (milk curd), phytobezoars (plant fibre) and medication bezoars. The term originates from the Arabic term badzehar, meaning "antidote," a reference to historical medicinal use of these concretions found in animal gastrointestinal tracts in the treatment of human poisonings.

Although small rectal bezoars may pass spontaneously, options for the care of patients presenting to clincians with symptomatic rectal bezoars include the use of enemas and extractions with conscious sedation or general anesthesia. ${ }^{2,3}$ Formation of bezoars from sunflower seeds may be more likely in children or preteens who are unable or unwilling to spit out the shells, particularly with flavoured shells.

This article has been peer reviewed.

Competing interests: None declared.

From the Faculty of Medicine (Minty), University of Manitoba, Winnipeg, Man., and the Division of Clinical Sciences (Kelly), Northern Ontario School of Medicine, Sioux Lookout, Ont.

CMAJ 2010. DOI:10.1503/cmaj.091991

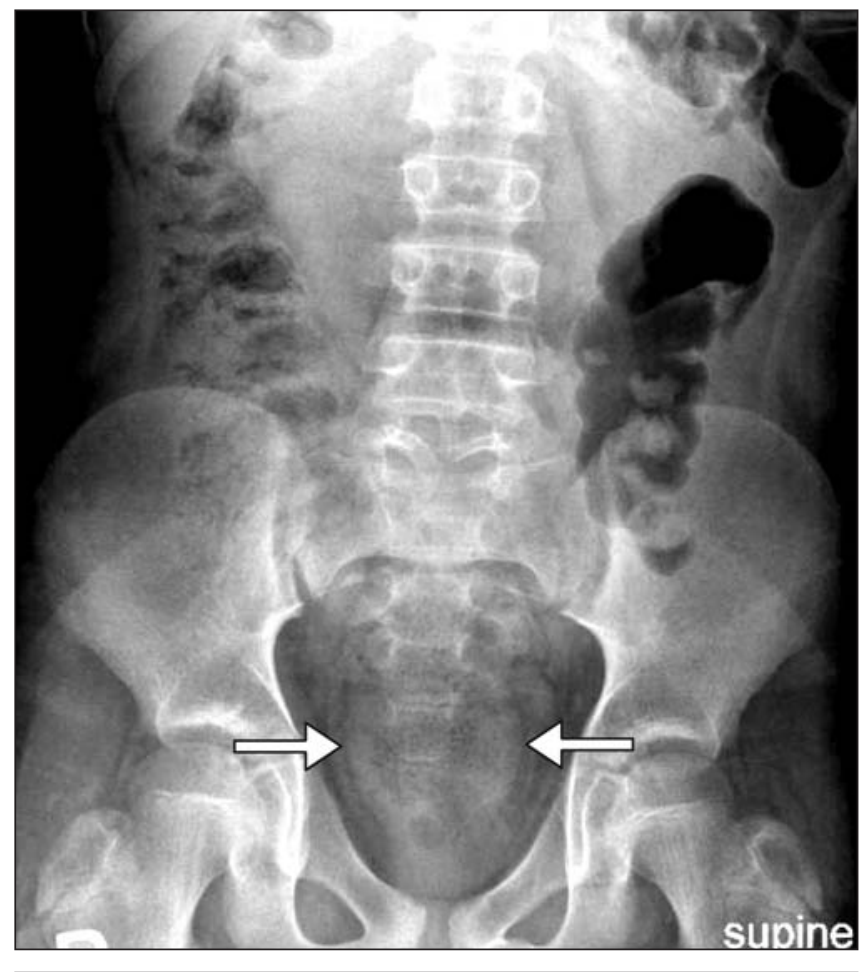

Figure 1: Abdominal radiograph showing a solid rectal bezoar (arrows) in a constipated eight-year-old boy following ingestion of flavoured unshelled sunflower seeds.

\section{REFERENCES}

1. Deslypere JP, Praet M, Verdonk G. An unusual case of trichobezoar: the Rapunze syndrome. Am J Gastroenterol 1982;77:467-70.

2. Eitan A, Katz I, Sweed Y, et al. Fecal impaction in children: report of 53 cases of rectal seed bezoars. J Pediatr Surg 2007;42:1114-7.

3. Purcell L, Gremse DA. Sunflower seed bezoar leading to fecal impaction. South Med J 1995;88:87-8.

Clinical images are chosen because they are particularly intriguing, classic or dramatic. Submissions of clear, appropriately labelled high-resolution images must be accompanied by a figure caption and the patient's written consent for publication. A brief explanation (300 words maximum) of the educational significance of the images with minimal references is required. 